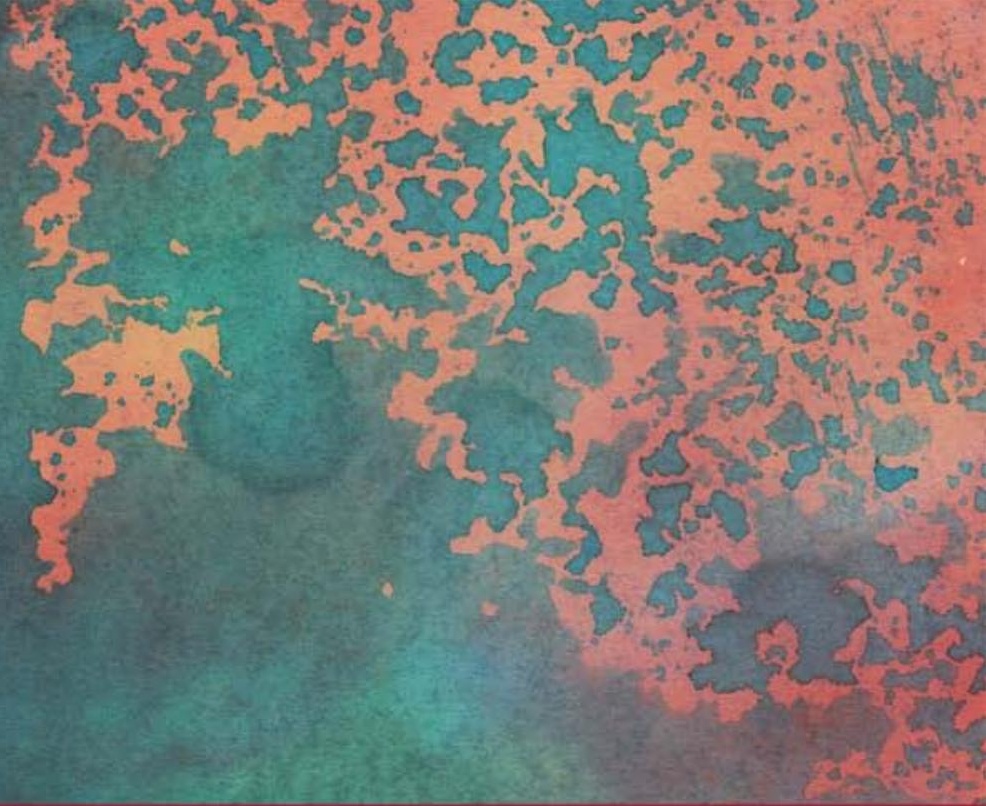

Routledge Studies in Ethics and Moral Theory

\title{
MORAL REALITY AND THE EMPIRICAL SCIENCES
}

Thomas Pölzler
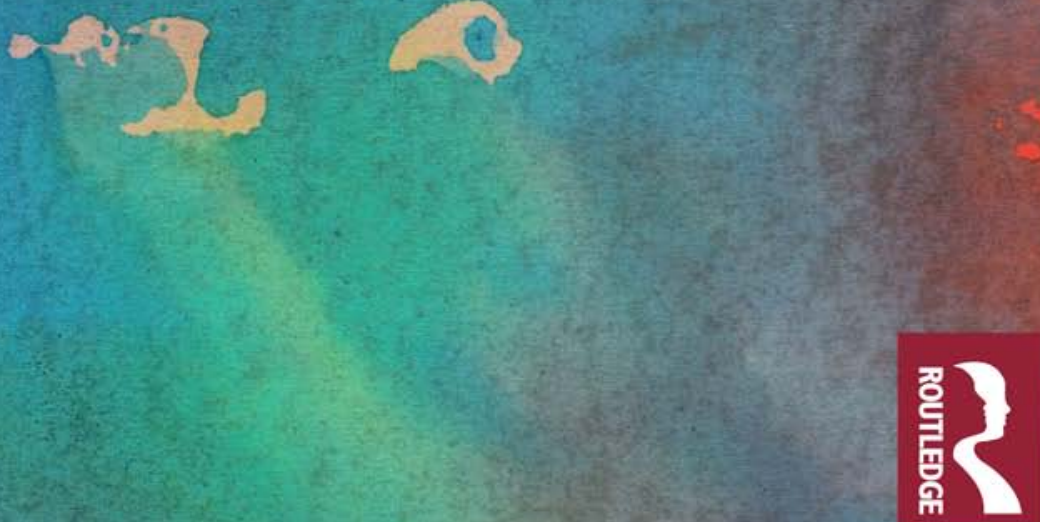


\section{Moral Reality and the Empirical Sciences}

Are there objective moral truths (things that are morally right or wrong independently of what anybody thinks about them)? To answer this question more and more scholars have recently begun to appeal to evidence from scientific disciplines such as psychology, neuroscience, biology, and anthropology. This book investigates this novel scientific approach in a comprehensive, empirically focused, partly clarificatory, and partly metatheoretical way. It argues for two main theses. First, it is possible for the empirical sciences to contribute to the moral realism/anti-realism debate. And second, most appeals to science that have so far been proposed are insufficiently empirically substantiated.

The book's main chapters address four prominent science-based arguments for or against the existence of objective moral truths: the presumptive argument, the argument from moral disagreement, the sentimentalist argument, and the evolutionary debunking argument. For each of these arguments Thomas Pölzler first identifies the sense in which its underlying empirical hypothesis would have to be true in order for the argument to work. Then he shows that the available scientific evidence fails to support this hypothesis. Finally, he also makes suggestions as to how to test the hypothesis more validly in future scientific research.

Moral Reality and the Empirical Sciences is an important contribution to the moral realism/anti-realism debate that will appeal both to philosophers and scientists interested in moral psychology and metaethics.

Thomas Pölzler is a post-doctoral researcher and lecturer in the Department of Philosophy at the University of Graz, Austria. He mainly works on moral psychology and metaethics. His articles have been published in journals such as Synthese, Review of Philosophy and Psychology, and South African Journal of Philosophy. 


\section{Contents}

Acknowledgments

vii

1 Introduction

1.1 Moral Realism and Anti-Realism 1

1.2 The Scientific Approach 6

1.3 Approach, Theses and Contents 7

2 Metatheoretical Considerations

2.1 Introduction 14

2.2 The Objection from Hume's Law 16

2.3 The Objection from Non-Naturalism 20

2.4 The Semantics and Philosophical Psychology Objection 25

2.5 The Logical Priority Objection 29

2.6 Conclusion 35

3 Folk Moral Realism

3.1 Introduction 43

3.2 Experience, Truth and Objectivity 46

3.3 Ordinary People 49

3.4 Research on Folk Moral Realism 52

3.5 Incomprehensiveness of Answer Choices 60

3.6 Conflation with Distinct Issues 64

3.7 First-Order Moral and Epistemic Intuitions 67

3.8 Classification and Instructions 70

3.9 Two Fundamental Worries 73

3.10 Conclusion 77

4 Moral Disagreement

4.1 Introduction 90

4.2 Disagreement and Morality 92 
vi Contents

4.3 Widespreadness 98

4.4 Eliminative Explanations 102

4.5 Research on Moral Disagreement 106

4.6 Defending One's Honor 108

4.7 Punishing an Innocent 113

4.8 Actions and Omissions 117

4.9 Conclusion 120

5 Moral Judgments and Emotions

5.1 Introduction 129

5.2 Moral Judgments' Association with Emotions 132

5.3 Sentimentalism's Empirical Predictions 137

5.4 Research on Moral Judgments and Emotions 143

5.5 The Co-Occurrence Hypothesis 146

5.6 The Causal Influence Hypothesis 150

5.7 The Causal Sufficiency Hypothesis 157

5.8 The Causal Necessity Hypothesis 163

5.9 Conclusion 169

6 The Evolution of Morality

6.1 Introduction 181

6.2 Moral Judgments and Adaptations 184

6.3 Variants of the Adaptation Hypotheses 188

6.4 Debunking Requirements 191

6.5 Research on the Evolution of Morality 195

6.6 The Argument from Design 199

6.7 The Universality Argument 203

6.8 The Poverty of Stimulus Argument 207

6.9 Conclusion 211

7 Conclusion

7.1 Comprehensiveness 225

7.2 Empirical Focus 226

7.3 Clarificatory Focus 227

7.4 Metatheoretical Considerations 229

Index 